\title{
SURVEY OF FIELD THEORY
}

\author{
AUTUMN MEETING OF THE PHYSICAL SOCIETY
}

$\mathrm{M}$ OST meetings of the Physical Society are intended either for the presentation of original papers or for hearing a special lecture by a distinguished scientist, usually the recipient of one of the Society's awards. The meeting held at the University of Birmingham on December 14-15 was of a rather different type. It may fairly be described as a conducted tour of one of the most interesting regions of the frontier of our present knowledge. The 'guides' were a team of specialists on field theory, under the leadership of Prof. R. E. Peierls, who gave the introductory lecture on the first day, when the president of the Physical Society, Prof. H. S. W. Massey, took the chair. The meeting was intended for experimentalists with a general knowledge of quantum mechanics and for theoreticians who do not specialize in field theory.

The lectures themselves were highly condensed summaries, so that it is not possible to summarize them further; but a general indication of their contents may be of interest to readers of Nature. Prof. Peierls, in the opening lecture, introduced the fundamental ideas, starting with a consideration of the normal modes of vibration of a solid. He emphasized the method of specifying quantum numbers for the different frequencies and derived from this the picture of 'sound quanta'. These sound quanta, known as 'phonons' in the physics of the solid state, carry the vibrational energy like separate particles. Prof. Peierls then discussed the Fourier analysis of the electromagnetic radiation field and its quantization. Again the quantum numbers for different frequencies specify the field, and the photons replace the phonons. He extended the description to static fields considered in terms of an exchange of longitudinal photons between the charges. The skeleton in the cupboard-the infinite energies-was brought out, rattled and then put back again. Field theorists appear to have a nibrmal vibration between two states: in one they believe they have solved the problem of the infinities, and in the other they know that they have not. Just at present, the first state seems to have the higher occupation number. Prof. Peierls described the virtual processes in which the field theorist becomes a dishonest accountant who embezzles energy but is never found out because he makes restitution within a time fixed by the uncertainty relation.

Dr. A. Salam (St. John's College, Cambridge) gave a more detailed analysis of field quantization and extended the analysis to a field of "photons of nonzero rest mass" defined by the Klein-Gordon equation. He showed that the 'particles' had some at least of the properties of $\pi$-mesons. He expounded and re-interpreted the Dirac theory of the electron. Dr. P. T. Matthews discussed interaction between fields and analysed a number of virtual processes. These virtual processes play a very important part in, and are a distinctive feature of, modern field theory. The scattering of a photon of frequency $v$ by an atom which has two states of energy $E_{1}$ and $E_{0}$ is regarded as including an intermediate process in which the photon is absorbed and the atom goes from $E_{0}$ to $E_{1}$; but since $h_{\nu}$ is not even approximately equal to $E_{1}-E_{0}$, energy is not conserved in this process. However, there is a second process in which the photon is emitted in a new direction and the atom returns to its original state. The second stage also 'breaks' the conservation law; but the two stages taken together do not, and there is no observable breach of the law. The 'ordinary physicist' who is just reconciling himself to this situation is then told that he must also accept a situation in which the photon is emitted from the atom in changing from state $E_{0}$ to state $E_{1}$, that is, 'before' the absorption of the incident photon. He is in the position of a bank manager who has agreed, in principle, that he will grant overdrafts and is then approached by someone who wishes to 'open an account' with an overdraft! As Dr. Matthews showed, there is no logical difference, but the psychological impact of the unfamiliar idea is sharper. He showed that successive virtual processes may produce unexpected observable effects. This gave a theory of the Lamb-Retherford shift and of the 'anomalous' magnetic moment of the electron. He explained the difficulty of meson theory which arises because the fundamental constant $g^{2} / \hbar c$ is probably of order 10 , whereas the corresponding constant in electron theory, $e^{2} / \hbar c$, is $1 / 137$.

During the discussion on these papers, experimentalists asked what the field theorists had to say about experiments in which particles seem to be very individual; for example, the observation of the track of a meson in an emulsion. Prof. Peierls stated the conditions in which the particle concept remains useful, but emphasized that the field concepts are an essential feature of any relativistic theory of interactions. There was a certain amount of friendly banter between the lecturers and some of the experimentalists in the audience concerning the question whether theory had preceded or followed certain experimental results. If an onlooker may comment on this private contest, I feel that life would be dreadfully dull for the experimentalist if the theoretician could predict in advance the results of his experiments. The theory which is most useful to the experimentalist is the one which most clearly defines a limited area in which crucial experiments may be expected to produce important results.

The three lectures on the second day dealt chiefly with field interactions. Dr. Matthews considered the information about spin, parity, etc., which is derived from studies of the disintegration of $\pi$-mesons and their interactions with nucleons. The independence of charge shown by nucleon-nucleon forces was discussed and the concept of isotopic spin was introduced. Dr. $G$. Feldman described meson production and scattering experiments, giving particular attention to the high-energy resonance effects obtained with protons produced in the large accelerators. Prof. Peierls gave the concluding lecture, in which he summed up the earlier discussions and described some of the difficult unsolved problems connected with the heavier mesons and the hyperons. He referred-perhaps a little 
wistfully-to the period in the 'thirtios when it was believed that an understanding of the dimensionless constant $e^{2} / \hbar c$ was just around the corner, and that with this understanding all problerns of fundamental particles and nuclear forces would be solved ... whereas to-day people don't know where to stop. . . .

The Physical Society and the organizers made the conference open without fee to all who were interested. Probably about half those present wero Fellows or student members of the Society and rather more than half were visitors to Birmingham. The total attendance was 135. Among this large number, there must have been a few whose background knowlodge was insufficient, but the interest and enthusiasm of the meeting was maintained throughout; the audience at the last lecture was not noticeably less than that at tho first. Inquiries revealod a gonoral feeling that an additional day or half-day to give time to assimilate the material would have been useful; but this statement was repeatedly accompanied by expressions of admiration for the excellence of the lectures. It was possible to treat so much material in a short time only because very great care had been taken to devise a treatment which avoidod all purely mathematical difficulties while revealing the essential unsolved problems of physical understanding.

In concluding this report, it is reasonable to ask whether this meeting should form an example for some future meetings of the Physical Society. If specialists in some other fields are prepared to give as much thought to the problems involved in explaining their work to other physicists, then they may also succeed; for example, a similar treatment of problems of supersonic flow might be very interesting. Other seientific sociotios may also find occasional meetings of this type acceptable to their members.

R. W. DrTchBuRn

\section{THE GEOGRAPHICAL ASSOCIATION}

$\mathrm{T}$ HE annual conference of the Geographical Association held at the London School of Economics during January 4-7 concluded a further eventful year in the lifo of tho Association, although the year's activities were sadly clouded by the death of Dr. O. J. R. Howarth, the immediate pastpresident, and also of Sir John Myros, a trustee, past-president and very staunch friend of the Association.

A very successful spring conferenco was held amid delightful surroundings at Exeter ; and the summer school, under the leadership of Mr. R. C. Honeybono and Dr. K. A. Sinnhuber, embarked on a new venture by moeting at Sistrans, near Innsbruck. A second party of members also attended in August the International Conference of Teachers of Geography held at Hilversum. As an outcome of this meeting the Geographical Association's office was adopted as the headquarters for the International Union of Associations of Teachers of Geography. As the central co-ordinating body, the Association has now assumed responsibility for the development and exchange of ideas among teachers of geography throughout the world. The Association has also sponsored courses for teachers in co-operation with the Norfolk Education Committee at Wymondham College, with the Derbyshire Education Committee at Buxton, with the Lancashire Education Committee at Manchester, and with Institutes of Education at London, Nottingham, Leeds and Reading.

A lively branch activity continues, five now branches being formed during the year, thus bringing tho total to forty-six, and the momborship has risen accordingly and now approaches the four thousand mark. The Association has watched with care the status of geography in the schools, and one important matter upon which questions were asked in the House of Commons was concerned with the changing regulations of the Scottish Universities Entrance 13oard. Action was taken jointly with the Royal Geographical Society and the Institute of British Geographers in this instance. At present considerable interest is focused upon the position of geography in secondary modern schools, cormprehensive schools and technical schools.

The three hundred and fifty teachers and lecturers who attended the annual conference were thus able to note with satisfaction a yoar of continuing vigorous activity under the presidency of Prof. S. W. Wooldridge. In a stimulating and provocativo presidential address on the "Status of Geography and the Role of Field-work", Prof. Wooldridge dirccted attontion to the need for a closer liaison between university and school practitioners of the subject, and to the problem of achieving balance between the presentation of matter and methods of teaching in the training colloges. The principles of field-work were enumerated and the need for local studies was emphasized, while the work of the Council for the Promotion of Ficld Studies was described together with the geographical facilities available at the four centres at Juniper Hall, Flatford Mill, Malham Tarn and Dale Fort.

The wide range of interests of the geographer was well illustrated by the supporting lectures: Mr. 'T. H. Elkins spoke on Liège and the problems of southern Belgium, Mr. D. J. Sinclair gave the results of a study in historical geography of some Surrey farms in the eighteenth and nineteenth centuries, Dr. F. G. Hannell lectured on the activities of the British Schools Exploring Society, and Mr. R. C. Honoybone presented an account of the summer school's alpine field-studies.

Educational aspects centrod on a lecture by Mr. Charles Armour (of the British Broadcasting Corporation) on sohool broadcasting and the teaching of geography, the talk being enlivened by recorded extracts from programmes: and on three symposia arranged by section committees. One dealt with problems of geography teaching and their relation to preparation for the university, a second discussed the General Certificate of Education of the Associated Fxamining Board, and a third-supported by a demonstration class-considered techniques of diagram and map-making in class. A selection of recent geographical films was shown during the meeting, and Prof. P. W. Bryan onco again contributed a 'Kodachrome' colour film, dealing on this occasion with the north-east Yorkshiro moors, wolds and coast. The customary publishers' exhibition of books, maps and appliances for the study and teaching of geography, supported by nearly forty publishers, was also arranged. The Association's Standing Committee for Visual Aids, in collaboration with the National Committeo for Visual Aids in Education and the Educational Foundation for Visual Aids, also mounted an exhibition of visual aids and 